\title{
Entomological Survey of Sandflies Vector (Diptera: Psychodidae: Phlebotominae) in Asser Region, Saudi Arabia
}

\author{
Fatima Elhadi, Amna Babeker, Hasabelrasol Elhaj, Fatima Alahmri, Lujin Almuflh, Rawabi \\ Alkibbashi
}

\section{ABSTRACT}

Phlebotomine sandflies (Diptera: Psychodidae) are the natural vectors of Leishmaniasis. This study aimed to identify the distribution and classification of phlebotomine sandflies vector in the Aseer region, Saudi Arabia. Twice entomological surveys were carried out in four geographical locations (Abha, Rijal Alma, Muhayil, and Asahel) within the Aseer Region during the period from November to December 2020. Phlebotomine sandflies were collected using light traps (10 traps/ month). Identification of species was done under a binocular microscope at $40 x$. Female and male specimens were identified by observing head and genital structures under the microscope using the morphological keys. Six species of phlebotomine sandflies with 107 were collected throughout the study period (November and December 2020). P.bergeroti species is the most abundant (54.2\%) followed by $P$. alexandri $(18.6 \%)$ and P.orientalis $(12.1 \%)$ of the total flies collected, while P.papatasi, P.sergenti, and P.arabicus were identified less abundance in Aseer region of the total flies collected . More phlebotomine sandfly species were found in the Abha province (38.3\%) followed by Rijal Alma province (31.7\%) while the least abundant collected in the Muhayil province $(8.4 \%)$ this study showed that P.bergeroti and P.alexandri are widespread in the Aseer region, specifically in Abha and the Rijal Alma provinces. More studies are needed to understand the preference, behavior and vectorial efficiency of sandfly vectors in Asser region.

Keywords: Asser, Leishmaniasis, Phlebotomine, Sandfly, Saudi Arabia.
Published Online: January 27, 2022

ISSN: 2684-5199

DOI : 10.24018/ejbio.2022.3.1.317

F. Elhadi*

Saudi Electronic University, College of Health Science, Saudi Arabia.

(e-mail: f.elhadi@seu.edu.sa)

A. Babeker

Basic Medical Science Department,

Applied Medical Science College, King

Khalid University, Saudi Arabia,

Department of Biology, University of Gadarif, Sudan.

(e-mail: ahemam@kku.edu.sa)

H. Elhaj

Vector Borne and Zoonotic Disease Administration, General Directorate of Health Affairs in Aseer Region, R.T.

Unit, Maraba, Saudi Arabia.

(e-mail: hfelhaj@gmail.com)

F. Alahmri

King Khalid University College of Applied Medical, Science Public Health Department, Saudi Arabia.

L. Almuflh

King Khalid University College of Applied Medical, Science Public Health Department, Saudi Arabia.

R. Alkibbashi

King Khalid University College of Applied Medical, Science Public Health Department, Saudi Arabia.

*Corresponding Author

\section{INTRODUCTION}

Sandflies mainly have an important role as potent vectors of leishmaniasis. The Leishmaniasis are a group of diseases caused by protozoan parasites, transmitted through the bites of infected female phlebotomine sandflies, which feed on blood to produce eggs (WHO, 2006). There are several different forms of leishmaniasis in people. The most common forms are cutaneous leishmaniasis, which causes skin sores, and visceral leishmaniasis, which affects several internal organs (usually spleen, liver, and bone marrow) (CDC, 2018), Cutaneous leishmaniasis worldwide occur in just six countries and KSA was one of these countries. Currently KSA is no longer on the list of the top 10 highest endemic countries worldwide, but it is still the fourth most endemic area in western Asia (Abuzaid et al., 2018).

The epidemiology of leishmaniasis depends on the characteristics of the parasite and sandfly species, the local ecological characteristics of the transmission sites, current and past exposure of the human population to the parasite, and human behavior (WHO, 2018).

Sandflies adults are small flies - only about $3 \mathrm{~mm}$ long and are golden, brownish, or gray colored. They have long, piercing mouthparts that are well adapted for sucking blood from their selected host. Sandflies hold their hairy-looking wings in a vertical V-shape when at rest, a characteristic that distinguishes them from some other small flies, Also, the six legs on the adults are extremely long, being longer than the insect's body (Orkin, 2019),

Three ways of detecting sandfly breeding places: the use of emergence traps placed over potential sources to catch newly emerged adult sandflies, flotation of larvae and pupae from the soil, etc., and desiccation of media to drive out the larvae (Feliciangeli et al,2004). Key to identify of sandflies species. 
Their length is 1.2-3.7 mm and yellowish in color, with conspicuous black eyes, and hairy bodies, wings, and legs. The oval lanceolate wings are carried erect on the humped thorax. Males possess long prominent genital Terminalia known as claspers. Females have a pair of anal recti. The wings are raised above the body. The apex of the wings is directed posterior and lateral. Legs are long and slender (Perfiliev, 1968).

Kingdom: Animalia

- Phylum: Arthropod

- Class: Insecta

- Order: Diptera

- Family: Psychodidae

- Genus: phlebotomus (Mustafa, 2016).

Studies of sandfly fauna in Saudi Arabia revealed the presence of 25 species (Lewis and Buttiker,1982) Nevertheless, two sandfly species; P.papatasi and P.sergenti were reported to increase the risk of CL transmission in the area studied in Saudi Arabia (Abdelwahab \& Abdelmohsin 2005; Ayman et al., 2008)

Personal protection and source reduction of sandfly vector remained an effective tool in the prevention of leishmaniasis (Feliciangeli et al.,2004). Targeting sandfly vector is required to improve the planning of cutaneous leishmaniasis prevention and control strategies. Therefore, this study was designed to identify the distribution and classification of phlebotomine sandflies in the Aseer region.

\section{MATERIALS AND Methods}

\section{A. Study Area}

The entomological survey was carried out in the Aseer region, located of the southwest in Saudi Arabia. It has an area of $81,000 \mathrm{~km}^{2}$, mountains, highlands, lowland, two rainy seasons, and low-level temperature (Wikipedia, 2013)

Four different provinces were included in this study considerable to have high prevalence of Cutaneous Leishmania according to annual report of ministry of health.

\section{B. Phlebotomine Sandflies Collection}

Sandflies were collected twice a week from four geographical locations within the Aseer region during the period from November to December 2020.

Light traps used to collect sandflies from different habitats locations (i.e. rocky areas, different vegetation covers, Wadi, etc...) and locations (i.e. indoors and outdoors). Two light traps used every night (10 traps/ month) between 18:00-06:00 HR. The traps hanged $20-30 \mathrm{~cm}$ above the ground level.

\section{Phlebotomine Sandflies Identification}

All adults of Phlebotomine sandflies from different collection sites transferred to the laboratory and placed in alcohol carefully mounted in Berlese's medium. (KillickKendrick et al., 1991).

The identification of species done under a binocular microscope at 40x. Female and male specimens identified by observing head and genital structures under the microscope using the morphological keys and characters of identification proposed by the main features used for sandfly identification include the female spermatheca, male Terminalia, the pharyngeal, and the cibarial tooth structures of both sexes
(Lewis \& Buttiker, 1982).

\section{Ethical Approval}

The study was approve by the Vector Borne and Zoonotic Disease Administration in Aseer region.

\section{E. Statistical analysis}

Entomological survey data was carefully recorded and entered into designed forms and Excel software for analysis.

\section{RESULT}

\section{A. Species Composition and Relative Abundance}

Six species of phlebotomus sandflies with the total of 107 flies were collected throughout the study area Table I: namely: (P.papatasi, P.bergeroti, P.sergenti, P.alexandri, P.orientalis, and P.arabicus). P.bergeroti is the most abundant (58.9\%) followed by P.alexandri (18.6\%) and P.orientalis $(12.1 \%)$ while the rest of species P.sergenti (6.5\%), P.arabicus (5.6\%) and P.papatasi $(2.8 \%)$ were less abundance in Aseer Region.

Furthermore P.sergenti (9.9\%) and P.arabicus (8.1\%) were most abundant in December compared to November $(2.2 \%)$ respectively, and the P.papatasi is the lower abundant $(1.6 \%)$ in December compared to November $(4.3 \%)$.

TABLE I: RELATIVE ABUNDANCE OF REPORTED PHLEBOTOMUS SANDFLIES SPECIES IN ASEER REGION

\begin{tabular}{cccc}
\multicolumn{3}{c}{ Species } & \multicolumn{2}{c}{2020} & \multirow{2}{*}{ Total } \\
\cline { 2 - 3 } & Nov & Dec & \\
\hline \hline P.bergeroti Parrot & $27(58.6 \%)$ & $31(50.9 \%)$ & $58(54.2 \%)$ \\
P.alexandri Sinton & $9(19.4 \%)$ & $11(18 \%)$ & $20(18.6 \%)$ \\
P.orientalis Parrot & $6(13.0 \%)$ & $7(11.4 \%)$ & $13(12.1 \%)$ \\
P.sergenti Parrot & $1(2.2 \%)$ & $6(9.9 \%)$ & $7(6.5 \%)$ \\
P.arabicus Theodor & $1(2.2 \%)$ & $5(8.1 \%)$ & $6(5.6 \%)$ \\
P.papatasi (Scopoli) & $2(4.3 \%)$ & $1(1.6 \%)$ & $3(2.8 \%)$ \\
Total No. (Male/Female) & & & $107(59 / 38)$ \\
Sex ratio M:F & & & $1: 16$ \\
\hline \hline
\end{tabular}

Table II Shows that more abundance of phlebotomus sandflies species was found in Abha province (38.3\%) followed by Rijal Alma (31.7\%) and Alsaheil (21.4\%) of the total flies collected, while the low abundance of sandfly species was observed in Muhayil (8.4\%).

TABLE II: GEOGRAPHICAL DISTRIBUTION OF PHLEBOTOMUS SANDFLIES COLLECTED IN DIFFERENT PROVINCES OF THE

\begin{tabular}{ccccc}
\multicolumn{5}{c}{ ASEER REGION } \\
\hline \hline \multirow{2}{*}{ Area } & Nov & Dec & Total & $\begin{array}{c}\text { Relative abundance } \\
\%\end{array}$ \\
\cline { 2 - 4 } & & & & 38.3 \\
Abha & 32 & 9 & 41 & 31.7 \\
Rijal Alma & 10 & 24 & 34 & 8.4 \\
Muhayil & 3 & 6 & 9 & 21.4 \\
Alsaheil & 1 & 22 & 23 & \\
Total & 46 & 61 & 107 & \\
\hline \hline
\end{tabular}

Table III shows 46 flies were collected in November 2020. P.bergeroti (58.6\%) was the most abundant species regarding density and/or distribution. P.alexandri was second in abundance $(19.4 \%)$ and the P.orientalis was third. For a collection of P.arabicus and P.sergenti were extremely low $(2.2 \%)$. 
TABLE III: RELATIVE ABUNDANCE OF PHLEBOTOMUS SANDFLIES SPECIES COLLECTED IN DIFFERENT PROVINCES OF THE ASEER REGION (NOVEMBER 2020)

\begin{tabular}{ccccccc}
\hline \hline Species & Abha & $\begin{array}{c}\text { Rijal } \\
\text { Alma }\end{array}$ & Muhayil & Alsaheil & \multicolumn{2}{c}{ Total } \\
\hline $\begin{array}{c}\text { P.papatasi } \\
\text { (Scopoli) }\end{array}$ & 0 & 1 & 0 & 1 & 2 & 4.30 \\
$\begin{array}{c}\text { P.bergeroti } \\
\text { Parrot }\end{array}$ & 24 & 2 & 1 & 0 & 27 & 58.60 \\
$\begin{array}{c}\text { P.sergenti } \\
\text { Parrot }\end{array}$ & 1 & 0 & 0 & 0 & 1 & 2.20 \\
$\begin{array}{c}\text { P.alexandri } \\
\text { Sinton }\end{array}$ & 6 & 1 & 2 & 0 & 9 & 19.40 \\
$\begin{array}{c}\text { P.orientalis } \\
\text { Parrot }\end{array}$ & 0 & 6 & 0 & 0 & 6 & 13.00 \\
$\begin{array}{c}\text { P.arabicus } \\
\text { Theodor }\end{array}$ & 1 & 0 & 0 & 0 & 1 & 2.20 \\
\hline \hline Total No. & 32 & 10 & 3 & 1 & 46 & 100 \\
\hline \hline
\end{tabular}

Table IV shows a total of 61 Phlebotomus sandflies species. P.bergeroti (50.9\%) was the most abundant species, P.alexandri was second in abundance $(18 \%)$ and the P.orientalis was third, while P.papatasi was very low density (1.6\%).

TABLE IV: RELATIVE ABUNDANCE (\%) OF PHLEBOTOMUS SANDFLIES SPECIES COLLECTED IN DIFFERENT PROVINCES OF ASEER REGION (DECEMBER 2020)

\begin{tabular}{ccccccc}
\hline \hline Species & Abha & $\begin{array}{c}\text { Rijal } \\
\text { Alma }\end{array}$ & Muhayil & Alsaheil & \multicolumn{2}{c}{ Total } \\
\hline $\begin{array}{c}\text { P.papatasi } \\
\text { (Scopoli) }\end{array}$ & 0 & 0 & 1 & 0 & 1 & 1.63 \\
$\begin{array}{c}\text { P.bergeroti } \\
\text { Parrot }\end{array}$ & 7 & 12 & 2 & 10 & 31 & 50.81 \\
$\begin{array}{c}\text { P.sergenti } \\
\text { Parrot }\end{array}$ & 0 & 0 & 3 & 3 & 6 & 9.83 \\
$\begin{array}{c}\text { P.alexandri } \\
\text { Sinton }\end{array}$ & 2 & 7 & 0 & 2 & 11 & 18.03 \\
$\begin{array}{c}\text { P.orientalis } \\
\text { Parrot }\end{array}$ & 0 & 0 & 0 & 7 & 7 & 11.47 \\
$\begin{array}{c}\text { P.arabicus } \\
\text { Theodor }\end{array}$ & 0 & 5 & 0 & 0 & 5 & 8.19 \\
\hline \hline $\begin{array}{c}\text { No. } \\
\text { Total }\end{array}$ & 9 & 24 & 6 & 22 & 61 & 100 \\
\hline \hline
\end{tabular}

Cutaneous leishmaniasis (CL) disease is endemic in many regions of KSA, including the Asser region, the entomological survey of phlebotomus sandflies has been conducted in four sites in the Asser region, This entomological survey found 6 species of phlebotomus sandflies (P.sergenti, P.papatasi, P.arabicus, P.alexandri, $P$.orientalis, P.bergeroti) totaling of 107 flies throughout the study period (November (46), December (61)),

The result here showed a very high density of phlebotomus sandflies when compared with the density of phlebotomus flies reported in 2019 (22 sandflies) by vector control department in the same period (Annual report. Research and Training Unit.2020)

This huge difference between 2020 and 2019 result might indicate the control measures activities in 2019 were carried out before the entomological survey. the P.bergeroti was the most abundant species in both months, which is similar to the study, conducted earlier (Abdelwahab \& Abdelmohsin, 2005) in Southwest Saudi Arabia, which found the same.

These results also agree with the annual Vector control program report for 2019, which found P.bergeroti was the most abundant species in November 2019 but in December, the P.bergeroti was not detected, the dominance of P.bergeroti species in the Aseer region might be attributed to the high altitude and climatic conditions in the area.

These results confirm that P.bergeroti and P.alexandri are widespread in the Kingdom of Saudi Arabia, as well as in the Aseer region specially Abha and the Alsaheil. Regarding other phlebotomus species, our study found P.papatasi and P.arabicus were very low density in December and November, this is in line with a study conducted in Al-Bha, Saudi Arabia (Said et al., 2010) and not agree with the study conducted in Southwest Saudi Arabia (Lewis \& Buttiker 1982), which found P.orientalis and P.alexandri had very low density. According to literatures review, adult females are the only hematophagous stage; biting rates in a particular area would be strongly linked to the abundance of adult females (ECDC, 2021).

The abundance of females here is nearly equal to males this is not agreed with the study in ALmadina and western Saudi Arabia (Ayman et al., 2008) which found variation in the male /female sex ratio of the different species.

The study also showed a large difference between the abundance of sandfly at low and high altitudes. The highest abundance of flies was collected in the Abha highlands. while the lowest abundance of flies was collected in the in Muhayil and Sahel lowlands and this varies with the study conducted in southern Turkey Anatolia, (Simsek et al., (2007) which found the highest abundance of flies in the lowlands, also this is inconsistent with the study conducted in Al-Bha and in Asser region in KSA (Said.et al., 2010).

Our study suggests that the climate and elevation are associated with the high density of sandfly species, this suggestion is based on a high proportion of sandfly species in the Abha province if we exclude other factors that influence sandfly populations like vegetation, humidity, rainfall, temperature, soil composition.

\section{CONCLUSION AND RECOMMENDATION}

This study showed that the species of P.bergeroti and P.alexandri are widespread in the Aseer region specially Abha and the Alsaheil while P.papatasi and P.arabicus were very low density in December and November 2020. More research is needed to identify, biology, ecology, behavior of phlebotomus sandflies as well as to understand the transmission dynamics of cutaneous leishmaniasis (CL) disease in study area.

\section{ACKNOWLEDGMENT}

Special thanks should be given to the staff of Vector Borne and Zoonotic Disease Administration in Asser Region for their valuable technical support of this survey.

\section{REFERENCES}

Abdelwahab, A., I., \& Abdelmohsin, A., A., (2005), Distribution and population dynamics of Phlebotomus sandflies (Diptera: Psychodidae) in an endemic area of cutaneous leishmaniasis in Aseer Region, Southwestern Saudi Arabia, J. Entomology, 2(1), 102-108.

Abuzaid, A., A., Abdoon, A., M., Aldahan, M., A., Alzahrani, A., G., Alhakeem, R., F., Asiri, A., M., et al., (2018) Cutaneous Leishmaniasis in Saudi Arabia: A Comprehensive Overview. Vector borne and 
zoonotic diseases, 17(10), 673-684

Annual Eeport. Research and training Unit. (2020) Vector Borne and Zoonotic Disease Center. Ministry of Health, Maraba, Saudi Arabia.

Ayman, E., El-Badry, A., Al-Juhani, A., Ibrahim, E. K., Al-Zubiany, S. (2008), Distribution of sandflies in El-Nekheil province, in Al-Madinah Al-Munawwarah region, western of Saudi Arabia, Parasitol. Res, 103(1), 151-156.

CDC. (2018), Parasites leishmaniasis Center for Diseases Control and Prevention, U.S. Department of Health \& Human Services, Available at: https://www.cdc.gov/parasites/leishmaniasis/index.html

ECDC. (2021), Phlebotomine sandflies, disease vector, Factsheet for experts (europa.eu), European Centre for Disease Prevention and Control, Available from: https://www.ecdc.europa.eu/en/diseasevectors/facts/phlebotomine-sand-flies

Feliciangeli, M., D., (2004), Natural breeding places of phlebotomine sandflies, Medical and Veterinary Entomology, 18(4), 453.

Killick-Kendrick, R., Tang, Y., Killick-Kendrick, M., Sang, D., K., Sirdar M., K., Ke, L., et al (1991) The identification of female sandflies of the subgenus Larroussius by the morphology of the spermathecal ducts, Parassitologia, 33(Suppl.1), 335-347.

Lewis, D., \& Buttiker, W. (1982), Insects of Saudi Arabia: the taxonomy and distribution of Saudi Arabian Phlebotomus sandflies (Diptera: Psychodidae), Fauna of Saudi Arabia, 4, 353-397.

Mustafa, M., M., (2016), Assessment of the use of impregnated bed nets in prevention and control sandfly bites in an endemic area with visceral leishmaniasis, Eastern Sudan- Int $J$ Community Med Public Health, 2016; 3: 3151-6.

Orkin. (2019) Facts, identification, control, Available from: https://www.orkin.com/flies/sand-flies

Perfiliev, P., P. (1968) Fauna of Phlebotomidae (sandflies) Diptera, Acad. Sci. 93(3): III (2).

Doha S., A., Samy, A., M. (2010), Bionomics of phlebotomine sandflies (Diptera: Psychodidae) in the province of Al-Baha, Saudi Arabia, Mem Inst Oswaldo Cruz, Rio de Janeiro, 105(7), 850-856.

Simsek, F., M., Alten, B., Caglar, S., S., Ozbel, Y., Aytekin, A., M., Kaynas, S., et al, (2007) Distribution and altitudinal structuring of phlebotomine sandflies (Diptera: Psychodidae) in southern Anatolia", Turkey: their relation to human cutaneous leishmaniasis. J Vector Ecol, 32(2), 26979.

WHO (2018), Leishmaniasis? World Health Organization.U.S. Available from: http://www.who.int/news-room/fact sheets/detail/leishmaniasis

WHO Report? (2006), Control of leishmaniasis. World Health Organization. Executive Board. 118 th session.

Wikipedia free encyclopedia. (2013), Asir Province, Available from: https://en.wikipedia.org/wiki/\%27Asir_Province. 